\title{
Vino para sentir. Nuevas construcciones identitarias en Rioja Alavesa
}

\author{
Ruth Marañón Martínez de la Puente. Universidad de Granada \\ Recepción: 12 de abril de 2015 | Revisión: 30 de mayo de 2015 | Aceptación/Publicación: 24 de julio de 2015 \\ Correspondencia: ruthmaranon@hotmail.com | catayarte@gmail.com | http://hdl.handle.net/10481/37127
}

\begin{abstract}
Resumen: En el marco de la comarca vasca de Rioja Alavesa, se llevó a cabo el I. Curso-Taller de Arte y Enología el pasado mes de julio de 2014. Este curso tenía la finalidad de trabajar a través de la cultura del vino y con la mediación artística la identidad de Rioja Alavesa, concepto en renovación debido a las nuevas circunstancias sociopolíticas de la comarca. En este artículo describimos esta propuesta (metodología, actividades y resultados) y su utilidad de cara a esta redefinición identitaria.
\end{abstract}

Palabras clave: Rioja Alavesa | Vino | Identidad | Enocultura | Patrimonio

FEEL THE WINE. NEW IDENTITY'S CONSTRUCTIONS IN RIOJA ALAVESA

Abstract: This research is set up in Rioja Alavesa, a Basque Country's region where we did the first Conference on Art and Oenology in July of 2014. This conference had the purpose of work through art and culture of wine the identity of Rioja Alavesa. This concept is in continuous renovation because of sociopolitical circumstances. With this article, we describe this proposal (methodology, activities and results) and its usefulness for this identity redefinition.

Keywords: Rioja Alavesa | Wine | Identity | Eno-culture | Heritage

\section{Introducción}

Rioja Alavesa conforma una de las 7 comarcas o cuadrillas en las que queda legislativamente dividida Álava (País Vasco), teniendo unas características tanto geográficas como políticas muy peculiares que hacen de éste, un ámbito complejo tanto educativa como institucionalmente.

Su realidad social se vio afectada (al igual que el resto de País Vasco) por la lucha armada de ETA. Con su alto el fuego, se abre un nuevo momento histórico y social, aspecto que repercute directamente en nuestro ámbito de estudio.

Así, nuestra investigación busca re-definir, acorde a esta nueva realidad, Rioja Alavesa y su identidad, partiendo de dos pilares fundamentales: el arte y el vino, entendido como enocultura, o dicho de otro modo, como patrimonio.

De este modo, iniciamos diferentes actividades para poder responder a esta hipótesis desde una perspectiva plural, colectiva, en la que toda la sociedad participara aportando sus opiniones, ideas y sobre todo, añadiendo ese matiz de debate, de diálogo, de historia colectiva que tan enriquecedor resulta. En esta ocasión, tal y como describiremos a continuación, presentamos el caso concreto del I. Curso-Taller de Arte y Enología, celebrado el pasado mes de julio de 2014 en Laguardia.

\section{Vino para sentir: I. Curso-Taller de Arte y Enología}

Existen determinados productos agrarios que definen una región, un país e incluso a una determinada civilización. Cuando esto ocurre, inmediatamente el producto agrícola se convierte en el producto cultural de la zona, integrándose, de tal manera que es descrita como parte de su identidad.

Este es el caso de Rioja Alavesa (Palacios, 1978; Velilla, 1982, 1996; Pastor, 2013; Lakunza, 2013; Marañón 2012, 2013a, 2014b), que se caracteriza por ser una 
comarca enraizada a la cultura de la vid, aspecto que se denota en su paisaje: desde las faldas de la Sierra de Cantabria hasta la frontera natural del Río Ebro con La Rioja, sus campos son mares de viñedos que tornan el color de la comarca según la estación. Pero, a pesar de que ya de por sí el paisaje genera nuestra cultura desde las más primitivas a las más actuales (Convención de Florencia del Paisaje, 2000), no sólo se funde con el paisaje sino también con diferentes señas o notas que hacen del nexo vino-identidad un brindis patrimonial en torno a la cultura del vino, tales como lagares rupestres (como es el caso de Labastida), calados subterráneos (en Laguardia), casas solariegas que marcan su arquitectura según las necesidades/usos vitícolas (Lanciego, Elciego...) y por supuesto, las numerosas bodegas que crecen y se reparten por toda la geografía de la comarca (desde las más antiguas hasta las más contemporáneas).

En tiempos de la antigua Grecia, Roma, e incluso en Egipto, el vino era entendido como algo que guardaba relación directa con lo culto, y era por tanto, propio de pueblos "con cultura" en contra de los pueblos, por ejemplo, consumidores de cerveza (Miret i Nin, 2005).

El enlace entre arte y vino (como ha ido demostrando la historia del arte) nos habla de la influencia de éste en las diferentes culturas, dejando una huella patente de construcción identitaria (Miret i Nin, 2005), configurando en gran medida las formas de entender la sociología, de las relaciones que se dan en el pueblo/civilización y que construyen su cotidianeidad, sus costumbres. De tal manera que, con el paso de los años (incluso de siglos), ese savoir faire vitícola acaba constituyendo lo que denominamos tradición o, mejor incluso, nuestro patrimonio. En Rioja Alavesa, el viñedo y el vino siguen entendiéndose como una forma de cultura, de ser y de vivir.

La relación de arte-vino para este proyecto es entendida como una dualidad de carácter histórico, social (Miret i Nin, 2005; Quero, 2008; Suárez Sousa, 2009, 2014) y en relación directa con la importancia de ésta como construcción de civilizaciones, de pueblos... partiendo de los egipcios, Roma o Grecia, avanzando por diferentes etapas y estilos hasta el siglo XX, demostrando que, como dice Mauricio Wiesenthal "la historia del vino, es historia del arte".

Así, como decía, son múltiples los ejemplos que podemos hallar por toda Rioja Alavesa para descubrir que se trata de un elemento (el vino y su cultura) que podríamos definir como arquetipal, esto es, como un elemento que forma parte de nuestro imaginario y que ha construido y construye nuestro entorno, nuestra sociedad y nuestra identidad (véase la web de Dinastía Vivanco) en tanto que inconsciente colectivo -esa parte de la psique que conserva y transmite la común herencia psicológica de la humanidad- (León del Río, 2007: 37).

Es más, esta unión entre arte y vino que podría verse igualmente reflejada en la idea de constatación histórico-social (como veníamos diciendo), es asimismo un método para trabajar en torno al patrimonio y su interpretación, puesto que tiene un valor educativo en la medida en que repercute en la construcción de la identidad individual y grupal, ayudando a las personas a reconocerse a sí mismas a través de una mayor comprensión del entorno que las rodea (Gutiérrez, 2012: 283).

Esto es, este rico patrimonio material e inmaterial que supone la Enocultura en el contexto estudiado, en Rioja Alavesa, nos habla directamente de esa relación que guarda el patrimonio con la identidad, pero a su vez, la interrelación que supone como elemento de reconstrucción social y/o identitaria. 
Igualmente, el análisis de estas interrelaciones que se dan entre Enocultura y la población de Rioja Alavesa para reconstruir la definición de identidad desde el calibre del arte, puede resultar aún más interesante al encontrar puntos de nexo con la validez artística en procesos de este tipo (Barbosa, 2002, 2009; Moreno, 2010), ya que, además el Arte realmente es un vehículo que puede articular y regenerar situaciones y contextos (Pérez Rubio, 2009:9).

Y es que aquí el vino no es sólo entendido como un elemento patrimonial, es también la confluencia de sensibilidades y experiencias, lo que genera nuevas identidades (Fontal, 2013: 58).

Así pues, para buscar esa nueva definición identitaria, y fundando nuestras propuestas tras estos principios, decidimos crear una serie de actividades que dieran lugar a esta reconstrucción de una manera natural, despertando aquellas piezas claves de nuestro imaginario y que quedan subyacentes por sentirlas como inherentes.

Así, surgen diferentes propuestas, entre ellas este I. Curso Taller de Arte y Enología. Esta actividad, integrada dentro del conjunto de propuestas realizadas para la tesis doctoral que estamos elaborando, se realizó en las instalaciones de la Cuadrilla de Rioja Alavesa (sita en Laguardia), contando, además, con su apoyo institucional. Para este taller participaron 14 personas, (10 mujeres y 4 hombres), de edades comprendidas entre los 27 años la más joven y 61 el participante de mayor edad.

El curso-taller se desarrolló en cinco sesiones que quedaron divididas en dos partes: una teórica y otra práctica a modo de taller. En general, nuestro interés se centró en presentar diferentes temáticas o aspectos que maridaran con el carácter, personalidad o esencia de Rioja Alavesa, convergiendo puntos de encuentro, de diálogo y especialmente de reflexión sobre lo que somos, de dónde venimos y a dónde vamos.

Esto es, redescubrir qué subyace dentro de nuestro mundo sensible, de nuestro imaginario, desde una perspectiva artística y proponiendo el elemento vitícola como nexo. Y asimismo, definir de qué manera éste repercute entre nuestro "être-ensemble" (Maffesoli, 1979, 2003, 2007), esto es, en nuestras relaciones sociales que son las que, finalmente constituyen sociedad, y por ende, construyen Rioja Alavesa y su identidad.

Básicamente nos interesamos en una metodología artística y participativa, concretamente la Mediación Artística (Barbosa, 2002, 2009; Ciafardo, 2010; Lidón Beltrán, 2005; Domínguez-Toscano, 2006; Irwin, 2008, 2010; Klein, 2009; López Fdz. Cao, 2006; Moreno, 2005, 2010), en la que todos los participantes podían despertar por un lado su lado creativo, por otro lado profundizar en aspectos ya conocidos pero que era necesario revisar y por último, estimular una actitud reflexiva y crítica.

Esta metodología respeta y propone la diversidad cultural como parte necesaria y adecuada a la hora de entender el arte (en cualquiera de sus versiones: música, video, artes plásticas, visuales, etc.), pero lo realmente interesante de ésta es que parte de una problemática concreta. En nuestro proyecto esta idea es clave porque se basa en el conflicto identitario vasco (Mtz. Gorriarán y Aguirre, 1995) y más concretamente en el riojano-alavés.

Miret i Nin (2005) hacía referencia a las diferentes maneras en las que la relación de arte-vino-sociedad quedan patentes a través de diferentes tipos de obras, así pues, nosotros decidimos (apoyándose en Metodologías Artísticas e Investigación Basada 
en las Artes) que debía ser mediante la expresión plástica cómo debían definirse esas opiniones y reflejos de la realidad de Rioja Alavesa.

O dicho de otro modo, decidimos organizar cada sesión de este I. Curso-Taller con un objetivo y/o perspectivas completamente diferentes (a pesar del objetivo principal que une a todos: la re-definición identitaria) para conocer qué opinan los diferentes habitantes y vecinos de Rioja Alavesa sobre los distintos aspectos que configuran nuestra identidad desde una perspectiva artística.

Para ello pautamos como necesario conocer:

- Los diferentes contextos que representan espacios de cultura contemporánea de Rioja Alavesa, y cómo los visitantes nos enfrentamos a ellos (artística, patrimonial y culturalmente tanto como individuos como sociedad).

- Las sinergias que hay en Rioja Alavesa entre arte y enología y cómo influyen éstas en nuestro día a día.

- Repensar estas relaciones y sus espacios desde una perspectiva artística.

Sin duda, esto es esencial para nuestro proyecto ya que el autoconocimiento de las personas en un espacio limitado (entiéndase aquí Rioja Alavesa), refleja la dependencia mutua entre los habitantes, acentúa las diferencias y la especialización, y aumenta la complejidad y el dinamismo de la estructura social (Rojas Marcos, 1993: 234).

Al respecto, es interesante recordar cómo abríamos este artículo haciendo referencia directa a la Cultura del Vino entendida como patrimonio, siendo importante destacar llegados a este punto que el patrimonio es una herramienta indispensable para fundamentar de una manera coherente nuestra investigación; ya que aparte de ser el elemento que articula la identidad y el propio sentido de cultura (Estepa Jiménez y López Cuenca, 2006: 56), es según Ana Luengo (2013), lo que facilita la unión de los pueblos; es su identidad. Así, era esencial trabajar esta temática (esto es, el patrimonio como herramienta de reconstrucción identitaria -Arrieta Urtizberea, 2008; Calaf, 2003; Calaf y Fontal, 2006; Fontal, 2006, 2013; Gutiérrez Pérez, 2012; Huerta y De la Calle, 2013; UNESCO, 2007-) si queríamos trabajar el concepto/noción de identidad.
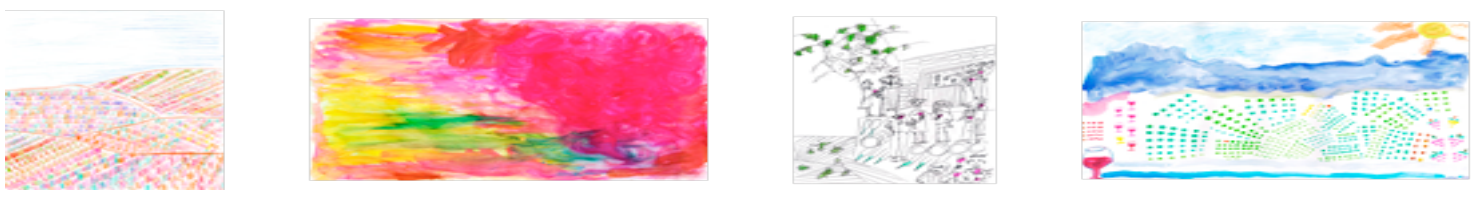

Fig. 1. De izquierda a derecha y de arriba abajo: Javier, Mónica, Amaia, Esther, MPedro, Carmen, Yolanda e Isabel (2014) Obras.

Por ello, para este I. Curso-Taller dedicamos las diferentes sesiones a, en primer lugar, a través de la historia del arte conocer cómo los diferentes artistas habian ilustrado la relación de arte y vino, siendo testigo y voz de las diferentes etapas no sólo estilísticas y artísticas, sino también históricas. Del mismo modo, trabajamos los principales aspectos en torno al patrimonio cultural del viñedo y los criterios y señas que marcan una candidatura UNESCO -tal y como es el caso de la actual revisión que debe hace Rioja Alavesa para su incorporación a la Lista Patrimonio Mundial LPM-, sin olvidar contrastar este aspecto con el de los "pequeños patrimonios" (Fontal, 2012; 
Calaf, 2005). Esto es, intentar demostrar cómo el patrimonio entreteje y conforma nuestra identidad y que, son los "pequeños patrimonios" los que realmente hacen patrimonio, consiguiendo así una conservación y protección reales, dotando por fin de valor a Rioja Alavesa y su patrimonio, y por ende, a lo que construye su identidad; o como diría Fontal (2013) trabajar del patrimonio a las personas. Por su parte, también una de las sesiones se centró en conocer una bodega a través de la experiencia de análisis fotográfico o Photography Based Research (Roldán, 2012) entendida como nuevo espacio musealizado; y cómo no, desde la actividad / experiencia de una cata artística (para más información, revisar Marañón Martínez de la Puente, R. 2014d), trabajando mediante sensaciones, olores, sabores y sinestesias, aquellos aspectos claves o relevantes de nuestra comarca.

Así, partiendo de estas bases se fue desarrollando este I. Curso-Taller, cuyos resultados demuestran que se trata de un territorio o una comarca que revisa en sus tradiciones y patrimonio(s), especialmente en el paisaje (Martínez-Novillo, 2005), sus formas y lenguajes identitarios.

De este modo, en las diferentes representaciones/ obras artísticas pudimos extraer las siguientes conclusiones:

- En general, se basaban en su mayoría en sus vivencias personales, dotando a las obras de un mayor valor y sobre todo, de personalidad, en definitiva, de identidad. Para ello, cada uno utilizó sus conocimientos artísticos para poder representar lo que deseaba mostrar.

- Pudimos descubrir de qué manera cada persona se relaciona con los espacios culturales de Rioja Alavesa y la temática enológica, lo cual nos habló en su mayoría de tres aspectos:

1. el disfrute del mundo vitivinícola;

2. y en contraposición, el aspecto laboral del vino;

3. y por último, la belleza del viñedo y concretamente la importancia de los espacios como bodegas o calados.

Esta triada nos habla de una manera muy clara qué papel juega el paisaje cultural del vino en nuestro día a día y de qué manera influye en la sociedad de Rioja Alavesa: es placer, es cultura en su interrelación con el resto de elementos arquitectónicos, yacimientos, etc... pero asimismo tiene ese papel de motor económico y laboral. En la basta amplitud del término: el vino es patrimonio.

- Mediante el objeto-arte se trabaja de manera más fluida, natural, sincera, ya que permite el afloramiento de reminiscencias o recuerdos personales que, en ocasiones sí se veían reflejadas en el valor o significado colectivo, proyectando un imaginario común.

- Las imágenes resumían, en su mayoría, de una manera muy gráfica los puntos clave de nuestra comarca, representando de manera continuada aquellos aspectos que durante los días del curso habíamos resaltado como esenciales para Rioja Alavesa. Esto es, repetían los mismos motivos o espacios / patrones, lo cual creó un material visual muy interesante que no hacían sino destacar, reafirmar, re-afianzar el paisaje del viñedo y la bodega como lugar de unión en torno a la cultura y patrimonio comunes: el vino y su cultura como elemento identitario en Rioja Alavesa. 


\section{Conclusiones}

A través de este curso-taller se abordaron propuestas identitarias desde diferentes maridajes (utilizando el argot enológico), provocando diferentes conclusiones plásticas muy evocadoras e intensos debates desde una perspectiva artística. Esto supuso una apertura a la redefinición, una reconstrucción plural, desde una narrativa artística colectiva que guardaba en muchas ocasiones significados comunes y raíces análogas.

La unión arte-vino generó sensaciones, emociones, inspiró, evocó y animó a nuestros participantes, ya que les fue más sencillo abordar el difícil, o al menos complejo, concepto-noción de identidad. De manera natural y con una implicación muy positiva en el curso, fueron aflorando esos pensamientos, la creatividad, la ilusión, el reconocimiento de lo que somos, del hallazgo de nuestra verdadera identidad.

Así, se aportaron numerosos datos y material, incluyendo aquí también sus consejos, sus conocimientos y sus experiencias. Cada uno, acorde a la (su) realidad, desde su enfoque y desde sus vivencias, han contribuido a que este proyecto sea precisamente lo que estamos buscando: una historia plural, colectiva, acorde a la realidad que en Rioja Alavesa se respira.

Por medio del arte y el patrimonio cultural del vino, gracias a esta experiencia en forma de curso-taller, hemos conseguido que la re-definición de la identidad esté cada día más cerca de alcanzarse.

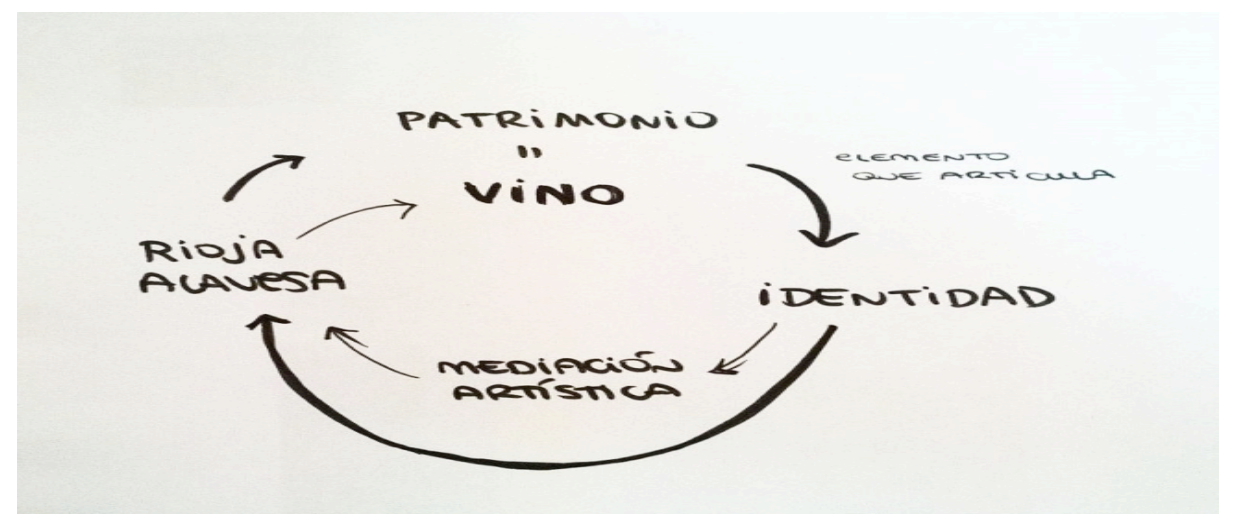

Fig. 2. Ruth Marañón Martínez de la Puente (2015). Conclusión- resumen visual.

\section{Bibliografía}

Arrieta Urtizberea, I. (2008): Participación ciudadana, patrimonio cultural y museos: entre la teoría y la praxis. Bilbao: Universidad del País Vasco- Euskal Herriko Unibertsitatea.

Barbosa, Ana Mae. (2002): Arte, educación y reconstrucción social. Cuadernos de pedagogía, 311. Marzo. 56-58.

Barbosa, Ana Mae. (2009): Arte, educación y cultura. Encuentro nacional de arte, diversidad cultural y educación. Perú, 5,6 y 7 de Noviembre.

Calaf, R. (coord.) (2003): Arte para todos. Miradas para enseñar y aprender el patrimonio. Gijón: Trea.

Calaf, R. y Fontal, O. (coord.) (2006): Miradas al patrimonio. Gijón: Trea.

Ciafardo, M. (2010): ¿Cuáles son nuestras sirenas? Aportes para enseñanza del lenguaje visual. Revista Iberoamericana de Educación. N ${ }^{\circ} 52 / 2$ 
Domínguez-Toscano, P. Ma . (2006): Arteterapia. Nuevos caminos para la mejora personal y social. Sevilla: Junta de Andalucía.

Estepa Jiménez, J. y Cuenca López, J. Ma. (2006): La mirada de los maestros, profesores y gestores del patrimonio. Investigación sobre concepciones acerca del patrimonio y su didáctica. EN Calaf, R. y Fontal, O. (coord.): Miradas al patrimonio. Gijón: Trea.

Fontal, O. (coord.) (2013): La educación patrimonial. Del patrimonio a las personas. Gijón: Trea.

Gutiérrez Pérez, R. (2012): Educación Artística y Comunicación del Patrimonio. Arte, Individuo y Sociedad, 24 (2). 283299.

Huerta, R. y De la Calle, R. (eds.) (2013): Patrimonios migrantes. Universitat de Valencia. Valencia.

Irwin, R. L. (2008): A/r/tography. EN: Given, L. (ed): The SAGE Encyclopedia of Qualitative Research Methods. CA: SAGE, Thousand Oaks. 26-29.

Irwin, R. L. (2010): A/r/tography. EN Kridel, C. (Ed.): Encyclopedia of Curriculum Studies. SAGE. Thousand Oaks, CA. 42-43.

Klein, J-P. (2009): Arteterapia. Una introducción. Barcelona: Octaedro.

Lakunza, R. (2013): Rioja Alavesa. Placer para los sentidos. EN: ON, 254. Revista suplemento del Diario de Noticias de Álava, 42- 45.

Lidón Beltrán, C. (2005): Educación como Mediación en Centros de Arte Contemporáneo. Salamanca: Junta de Castilla y León y Universidad de Salamanca.

López Fdz. Cao, M. (2006): Lo posible como alternativa a lo real: lugares de creación. Un proyecto de re-construcción a través del arte. EN: Actas del I Congreso Internacional de Educación Artística y Visual ante el Reto Social, Cultura y Territorialidad. 54-56.

Maffesoli, M. (2007): En el crisol de las apariencias: para una ética de la estética. Siglo XXI, Madrid.

Maffesoli, M. (2003): Notes sur la postmodernité. Le lieu fait lien. Éditions du Félin, Paris.

Maffesoli, M. (1979): La Conquête du présent. Pour une sociologie de la vie quotidienne. PUF, Paris.

Marañón Martínez de la Puente, R. (2013b): Septiembre. Culture and landscape: an identity discourse in Rioja Alavesa. 1st Conference on Arts-Based and Artistic Research: Critical reflections on the intersection of art and research. (82-93). Barcelona: University of Barcelona.

Marañón Martínez de la Puente, R. (2014d): Catas artísticas: Enocultura y patrimonio en Rioja Alavesa. II Congreso Internacional de Educación Patrimonial, Madrid.

Marañón Martínez de la Puente, R. (2015): Bodega, patrimonio y fotografía. Un ejercicio de re-definición identitaria en Rioja Alavesa EN: Actas del V Congreso Internacional de Educación Artística y Visual. Educación Artística y Acción Social. Huelva.

Martínez Gorriarán, C. y Aguirre Arriaga, I. (1995): Estética de la diferencia. El arte vasco y el problema de la identidad 1882-1966. San Sebastián: Alberdania y Galería Altxerri.

Martínez-Novillo, A. (2005): El paisaje cultural y la historia. EN: De la Mata Gorostizaga, R. y Aguiló Alonso, M. (coord.): Paisajes culturales. Colegio de Ingenieros de Caminos, Canales y Puertos. Madrid. 13-20.

Marín Viadel, R. (ed.) (2005): Investigación en Educación artística: Temas, métodos y técnicas de indagación, sobre el aprendizaje y la enseñanza de las artes y culturas visuales. Universidad de Granada y Universidad de Sevilla. Granada.

Miret i Nin, M. (2005): El vino en el arte. Lunwerg Editores, Barcelona.

Moreno González, A. (2005). Educación Social: ámbitos de actuación y intervención socioeducativa a través del arte. Primer Congreso de Educación de las Artes Visuales. Actas del congreso. Terrassa. Septiembre 2005. 
Moreno González, A. (2010). La Mediación Artística: un modelo de Educación Artística para la intervención social a través del arte. Revista Iberoamericana de Educación, 52/2. Disponible en http://www.rieoei.org/expe/3422Moreno.pdf

Palacios, J. (1978): Rioja Alavesa. Historia-Política-Economía. Hordago, San Sebastián.

Pastor, A. J. (2013): Encuentros. Rioja Alavesa. Vitoria-Gasteiz: Sacal.

Rojas Marcos, L. (1993): La ciudad y sus desafíos. Héroes y víctimas. Espasa, Madrid.

Roldán, J. y Marín Viadel, R. (2012): Metodologías artísticas de Investigación en educación. Aljibe, Archidona (Málaga).

Suárez Sousa, S. J. (Coord.) (2009): Vinaletras, 2 cuaderno bianual de cultura y vino. Tacoronte-Acentejo. D.O. Tacoronte-Acentejo, Tenerife.

Velilla Córdoba, S. (1996): Rioja Alavesa. Sua, Bilbao.

Zoido Naranjo, F. (2002): Convención Europea del Paisaje. Florencia, 20.X.2000. EN: Zoido Naranjo, F. y Venegas Moreno, C. (coord.): Paisaje y ordenación del Territorio I. Consejería de Obras Públicas y Transportes. Sevilla. 337-341. 